\title{
Supercooling and Solidification Behavior of Phase Change Material
}

\author{
LinLin WEI ${ }^{11}$ and Kenichi OHSASA ${ }^{21}$ \\ 1) Formerly Graduate Student, Hokkaido University. Now at Nippon Metal Industry Co., Ltd., Hama-cho, Hekinan $447-8610$ \\ Japan. $\quad 2$ 2) Department of Materials Science and Engineering, Akita University, 1-1 Tegata Gakuenmachi, Akita 010-8502 \\ Japan.
}

(Received on January 6, 2010; accepted on June 7, 2010)

\begin{abstract}
Supercooling and subsequent solidification behavior of phase change materials (PCM) of sodium acetate trihydrate (SAT) and erythritol were studied by using a thermal analysis technique. A molten SAT specimen easily supercooled below $0^{\circ} \mathrm{C}$ and the observed maximum degree of supercoolimg was $89^{\circ} \mathrm{C}$. Three changes due to phase transformation were observed in the cooling curve of the SAT. First change corresponds to the precipitation of sodium acetate $\left(\mathrm{CH}_{3} \mathrm{COONa}\right)$, and second change is the recalescence due to the solidification of supercooled SAT. It was considered that third change corresponds to the solid state transformation of SAT. From the maximum degree of the supercooling of SAT, the solid/liquid interfacial energy of SAT was evaluated as $5.56 \times 10^{-2} \mathrm{~J} / \mathrm{m}^{2}$. The observed maximum degree of the supercooling of erythritol was $91^{\circ} \mathrm{C}$. An experiment to induce the nucleation in supercooled liquid of SAT was carried out and the effectiveness of the combination of the ultrasonic irradiation and the addition of nucleation catalysts was demonstrated.
\end{abstract}

KEY WORDS: phase change material; sodium acetate trihydrate; erythrtol; supercooling; solidification; nucleation.

\section{Introduction}

Recently, latent heat thermal storage technology attracted much attention for the storage of the waste energy evolved at factories such as ironworks. In a latent heat thermal storage system, thermal energy is stored by using Phase Change Material (PCM) where a large amount of heat is saved in the form of transformation latent heat. Trans-Heat system is an application of PCM, in which industrial waste heat is stored in a PCM and delivered to a wide area being away spatially from a heat source. This technology will be expected for contributing to the reduction in $\mathrm{CO}_{2}$ emission by reducing combustion of fossil fuel.

Sodium acetate trihydrate $(\mathrm{SAT})\left(\mathrm{CH}_{3} \mathrm{COONa} \cdot 3 \mathrm{H}_{2} \mathrm{O}\right)$ is a PCM with melting point of $58^{\circ} \mathrm{C}$ and used as a relatively low temperature heat source. Erythritol $\left(\mathrm{HOCH}_{2}[\mathrm{CH}(\mathrm{OH})]_{2}\right.$ $\left.\mathrm{CH}_{2} \mathrm{OH}\right)$ is a $\mathrm{PCM}$ with melting point of $119^{\circ} \mathrm{C}$ and expected to store the waste energy from heat sources with relatively higher temperature over $100^{\circ} \mathrm{C}$. A feature of these PCMs is a supercooling characteristic. In these PCMs, solidification does not occur at the melting point and the PCMs easily become supercooled state for a relatively wide temperature range. To start the solidification of the supercooled PCMs, nucleation inducement procedures are often needed such as the addition of nucleation catalysts, application of mechanical vibration and ultrasonic irradiation. Hence, the supercooling characteristic of PCMs was considered to be a bothersome feature for using PCM as a ther- mal storage device.

Recently, the concept of a supercooled thermal energy storage (super-TES) system is proposed. ${ }^{1-3)}$ In the system, a supercooled liquid of a PCM is kept at room temperature for a long time, and stored thermal energy is released at an arbitrary moment by solidifying the supercooled liquid of the PCM. In order to develop the super-TES system, control of the supercooling characteristic of a PCM must be required. A technique for the inducement of nucleation in the supercooled liquid of a PCM at an arbitrary moment will also be required for the development of the super-TES system. In order to control the supercooling and subsequent nucleation behavior of the PCMs, the understanding of the supercooling characteristics of the PCMs is important.

The aims of this study are 1) to investigate the supercooling and subsequent solidification behavior of the SAT and erythritol based on the thermal analysis method and 2) to examine the method for the inducement of the nucleation in supercooled liquid of the SAT for the purpose of the development of the super-TES system.

\section{Experimental Method}

\subsection{Materials and Thermal Analysis}

Sodium acetate trihydrate (SAT) $\left(\mathrm{CH}_{3} \mathrm{COONa} \cdot 3 \mathrm{H}_{2} \mathrm{O}\right)$ with purity of $99 \%$ and erythritol $\left(\mathrm{HOCH}_{2}[\mathrm{CH}(\mathrm{OH})]_{2}\right.$ $\mathrm{CH}_{2} \mathrm{OH}$ ) with purity of $98 \%$ were used as target materials. Specimens of $10 \mathrm{mg}$ in mass were used for thermal analyses 


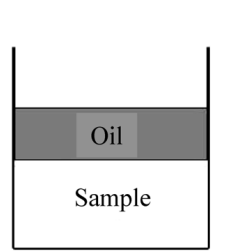

(a)

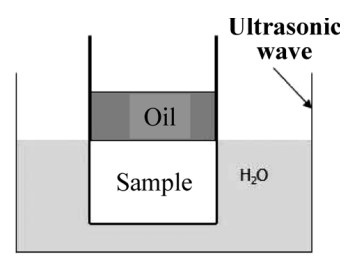

(b)
Fig. 1. Schematic view of experimental apparatus.

using TG-DTA (Thermo-Gravimetry Differential Thermal Analysis) and DSC (differential scanning calorimetry) under Ar atmosphere. Because of the limitation of working temperature ranges in TG-DTA and DSC, thermal analysis using a furnace with a working temperature range from -50 to $300^{\circ} \mathrm{C}$ was also carried out for specimens with 20-30 g in mass. The specimens were set in a glass beaker and the upper surface of the specimen was covered with an oil for the prevention of the decomposition of the specimen as shown in Fig. 1(a). The thermal analysis was carried out in air with heating and cooling rates of $3^{\circ} \mathrm{C} / \mathrm{min}$.

\subsection{Inducement of Nucleation in Supercooled Liquid}

A SAT specimen of $20 \mathrm{~g}$ in mass was set in a glass beaker and heated to $100^{\circ} \mathrm{C}$, then melted specimen was cooled to room temperature in air. The glass beaker with the specimen was set in an ultrasonic scrubber and ultrasonic irradiation was applied to the specimen as shown in Fig. 1(b). Ultrasonic irradiation experiment for the specimen with the addition of starch or metasilicate nonahydrate $\left(\mathrm{Na}_{2} \mathrm{SiO}_{3} \cdot 9 \mathrm{H}_{2} \mathrm{O}\right)$, that were known as a nucleation catalyst for SAT, was also carried out to examine the effect of the combination of the ultrasonic irradiation and the nucleation catalyst on the nucleation behavior of SAT. Solidification behavior of the specimen was monitored by measuring the change in temperature of the specimen.

\section{Results and Discussion}

\subsection{Supercooling and Solidification Behavior of SAT}

From the thermal analyses of SAT using TG-DTA and DSC, it was confirmed that the covered oil prevents SAT from the decomposition and the melting point of the SAT is $58^{\circ} \mathrm{C}$ from the endothermic peak. due to melting. However, solidification did not occurred during the cooling stage of molten SAT until room temperature.

To examine the supercooling behavior of molten SAT in a temperature range below room temperature, a thermal analysis of a specimen of $20 \mathrm{~g}$ in mass was carried out using the furnace with a working temperature range from -50 to $300^{\circ} \mathrm{C}$. Figure 2 shows a thermal analysis curve of the SAT specimen. Three changes due to phase transformation were observed in the cooling stage. First change occured at $66^{\circ} \mathrm{C}$, second change was the recalescence occurred at $-22^{\circ} \mathrm{C}$ and third one occured at $-17^{\circ} \mathrm{C}$. Figure 3 shows the result of an XRD analysis of the solidified specimen shown in the Fig. 2. Sodium acetate $\left(\mathrm{CH}_{3} \mathrm{COONa}\right)$ and sodium acetate trihydrate $(\mathrm{SAT})\left(\mathrm{CH}_{3}\right.$ $\left.\mathrm{COONa} \cdot 3 \mathrm{H}_{2} \mathrm{O}\right)$ were identified. From this result, it can be considered that the first change corresponds to the precipitation of sodium acetate $\left(\mathrm{CH}_{3} \mathrm{COONa}\right)$, and the second

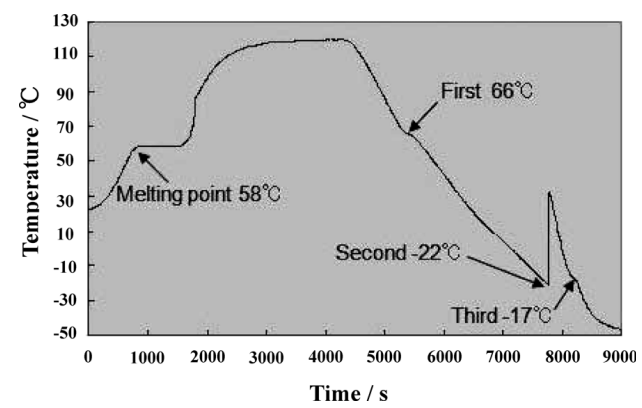

Fig. 2. Thermal analysis curve of sodium acetate trihydrate (SAT) of $20 \mathrm{~g}$ in mass.

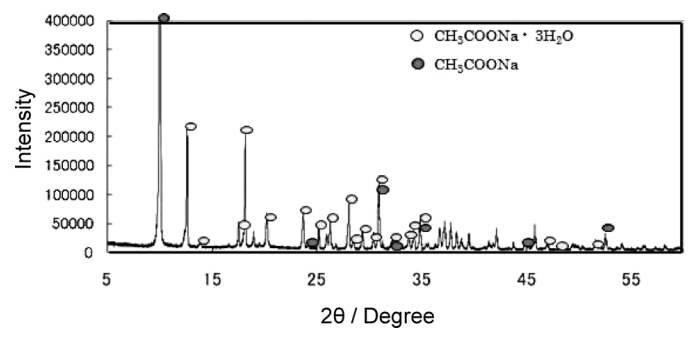

Fig. 3. XRD pattern of solidified sodium acetate trihydrate (SAT).

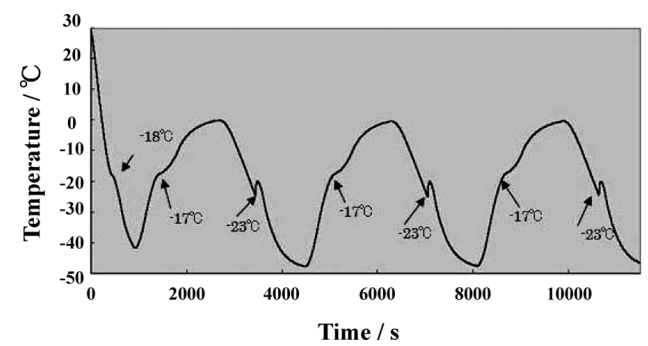

Fig. 4. Thermal analysis curve of solidified sodium acetate trihydrate (SAT) specimen in a temperature range below $0^{\circ} \mathrm{C}$.

change of the recalescence corresponds to the solidification of supercooled SAT. The third change has not been identified. To clarify the third phase transformation, heating and cooling procedures of a specimen after the second transformation was carried out. Observed thermal analysis curve is shown in Fig. 4. In the heating and cooling stages, changes in curve due to phase transformation were observed at almost same temperatures. From this result, it can be considered that the third change in the curve corresponds to the solid state transformation of the SAT. Since this unknown low temperature phase disappears at room temperature, the XRD analysis, which was done at room temperature, could not detect this phase. From the viewpoint of the use as a PCM, most heat energy is stored and released at the melting and solidification stage, and the latent heat energy of the low temperature solid state transformation can be regarded as negligible.

\subsection{Factors Influencing on Supercooling Behavior of SAT}

Figure 5 shows the effect of the superheat of molten SAT on the degree of the supercooling. A SAT specimen of $20 \mathrm{~g}$ in mass was melted in a glass beaker and kept at certain temperatures for $30 \mathrm{~min}$ and then cooled with cooling rate of $3^{\circ} \mathrm{C} / \mathrm{min}$. From the Fig. 5, a tendency can be seen 


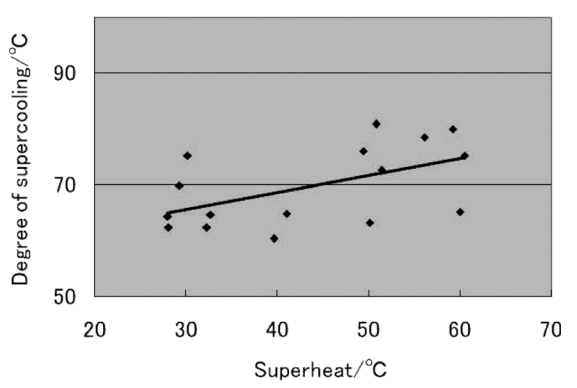

Fig. 5. Effect of the superheat of molten SAT on the degree of the supercooling.

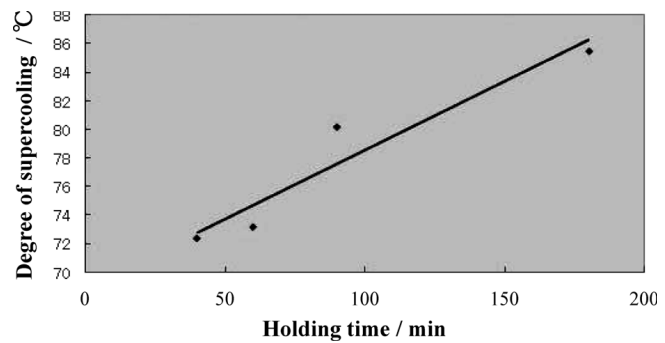

Fig. 6. Effect of the holding time of superheated molten SAT on the degree of supercooling.

Table 1. Comparison of material properties between sodium acetate trihydrate (SAT) and succinonitirile (SCN).

\begin{tabular}{|c|c|c|c|c|}
\hline Material & $\begin{array}{c}\text { Molecular } \\
\text { formula }\end{array}$ & $\begin{array}{c}\text { Melting } \\
\text { point }\end{array}$ & Latent heat & $\begin{array}{c}\text { S/L interfacial } \\
\text { energy }\end{array}$ \\
\hline $\begin{array}{c}\text { Sodium acetate } \\
\text { trihydrate }\end{array}$ & $\begin{array}{c}\mathrm{CH}_{3} \mathrm{COONa} \\
\cdot 3 \mathrm{H}_{2} \mathrm{O}\end{array}$ & $58^{\circ} \mathrm{C}$ & $205 \mathrm{KJ} / \mathrm{kg}$ & $\times$ \\
\hline succinonitrile & $\mathrm{CH}_{2}(\mathrm{CN})_{2} \mathrm{CH}_{2}$ & $58^{\circ} \mathrm{C}$ & $331 \mathrm{KJ} / \mathrm{kg}$ & $9 \times 10^{-3} \mathrm{~J} / \mathrm{m}^{2}$ \\
\hline
\end{tabular}

that the degree of supercooling increases with increase in superheat of the molten SAT. Figure 6 shows the effect of the holding time of the molten state of SAT on the supercooling behavior. A SAT specimens of $20 \mathrm{~g}$ in mass was melted in the glass beakers and kept at $110^{\circ} \mathrm{C}$ for given periods and then cooled with a cooling rate of $3^{\circ} \mathrm{C} / \mathrm{min}$. The degree of supercooling increased with increase in the holding time. The reason of these results shown in Figs. 5 and 6 can be explained as follows; heterogeneous nucleation catalysts existed in a molten SAT tends to disappear under the condition with higher superheat and longer holding time of a molten SAT.

\subsection{Homogeneous Nucleation Temperature of SAT}

To estimate the maximum degree of the supercooling of SAT, homogeneous nucleation temperature of SAT was examined. Based on the classical nucleation theory, homogeneous nucleation rate is expressed as follows ${ }^{4,5)}$;

$$
I=\frac{N k T}{h} \exp \left[\left(\frac{-16 \pi}{3}\right) \cdot\left(\frac{\sigma_{\mathrm{LC}}^{3}}{L_{\mathrm{S}}^{2}}\right) \cdot\left(\frac{T_{\mathrm{E}}^{2}}{\Delta T^{2}}\right) \cdot\left(\frac{1}{k T}\right)\right]
$$

Where, $I$ is homogeneous nucleation rate, $N$ is the number of atoms of a system, $k$ is the Boltzmann constant $\left(1.38 \times 10^{-23} \mathrm{~J} / \mathrm{K}\right), T$ is temperature $(\mathrm{K}), h$ is the plank's constant $\left(6.63 \times 10^{-34}\right), \sigma_{\mathrm{LC}}$ is solid/liquid $(\mathrm{S} / \mathrm{L})$ interfacial energy $\left(\mathrm{J} / \mathrm{m}^{2}\right), L_{\mathrm{S}}$ is latent heat $\left(\mathrm{J} / \mathrm{m}^{3}\right), \Delta T$ is degree of supercooling $(\mathrm{K})$ and $T_{\mathrm{E}}$ is the equilibrium melting point $(\mathrm{K})$.

In order to calculate the homogeneous nucleation rate of SAT, value of the $\mathrm{S} / \mathrm{L}$ interfacial energy of SAT was required. However, data of the $\mathrm{S} / \mathrm{L}$ interfacial energy of SAT was not found in literatures. Instead of SAT, the value of the $\mathrm{S} / \mathrm{L}$ interfacial energy of succinonitrile $\left(\mathrm{CH}_{2}(\mathrm{CN})_{2}\right.$ $\left.\left.\mathrm{CH}_{2}\right)\left(9 \times 10^{-3} \mathrm{~J} / \mathrm{m}^{2}\right)^{6}\right)$ was used for the calculation of the homogeneous nucleation rate of SAT. The reason for selecting the succinonitrile ( $\mathrm{SCN}$ ) is that the succinonitrile (SCN) has same melting point as that of the SAT. Comparison of the properties between SAT and succinonitrile $(\mathrm{SCN})$ is shown in Table 1.

Calculated homogeneous nucleation temperature of SAT from the Eq. (1) was $326 \mathrm{~K}\left(53^{\circ} \mathrm{C}\right)$. However, SAT speci- mens solidified below $0^{\circ} \mathrm{C}$ in the experiment. Obviously calculated homogeneous nucleation temperature is incorrect and this result shows that the $\mathrm{S} / \mathrm{L}$ interfacial energy of succionoitrile is inadequate for applying to SAT.

In the present study, an assumption was made; the observed maximum degree of supercooling in the experiment corresponds to the homogeneous nucleation temperature, and S/L interfaceial energy of the SAT was reversely determined by substituting the values of the maximum supercooling of $89 \mathrm{~K}$ and appropriate properties of SAT into Eq. (1). Obtained value of the $\mathrm{S} / \mathrm{L}$ interfacial energy of SAT is $5.56 \times 10^{-2}\left(\mathrm{~J} / \mathrm{m}^{2}\right)$. This value is located between values of the $\mathrm{S} / \mathrm{L}$ interfacial energy of succionotirile (SCN) $\left(\sigma_{\mathrm{SCN}}=9 \times 10^{-3} \mathrm{~J} / \mathrm{m}^{2}\right)$ and metals $\left(\sigma_{\mathrm{Al}}=1.6 \times 10^{-1}, \sigma_{\mathrm{Cu}}=\right.$ $\left.1.77 \times 10^{-1} \mathrm{~J} / \mathrm{m}^{2}\right){ }^{6}{ }^{6}$ It seems that the value of $5.56 \times 10^{-2}$ $\left(\mathrm{J} / \mathrm{m}^{2}\right)$ as the $\mathrm{S} / \mathrm{L}$ interfacial energy of the SAT is acceptable and it can be estimated that the homogeneous nucleation temperature of SAT is around $-30^{\circ} \mathrm{C}$.

\subsection{Supercooling and Solidification Behavior of Ery- thritol}

Figure 7 shows a result of the TG-DTA analysis of an erythritol specimen of $10 \mathrm{mg}$ in mass. Endothermic peak was observed at $119^{\circ} \mathrm{C}$ and the melting point of erythritol was estimated to $119^{\circ} \mathrm{C}$. An exothermic peak was observed at about $28^{\circ} \mathrm{C}$ due to solidification of the specimen in the cooling stage and the degree of supercooling is about $91^{\circ} \mathrm{C}$.

Figure 8 shows a thermal analysis curve of an eythritol specimen of $20 \mathrm{~g}$ in mass by using the furnace with a working temperature range from -50 to $300^{\circ} \mathrm{C}$. The specimen solidified at $59^{\circ} \mathrm{C}$ with degree of the supercooling of $60^{\circ} \mathrm{C}$. The degree of the supercooling decreased when the mass of the specimen increased from $10 \mathrm{mg}$ to $20 \mathrm{~g}$. The reason of this result might be explaned that the existing probability of effective nucleation catalysts in molten erythritol may increase with increase in mass of the specimen.

Homogeneous nucleation temperature of supercooled erythritol was calculated from the Eq. (1) by substituting the value of the $\mathrm{S} / \mathrm{L}$ interfacial energy evaluated in the Sec. 3.3 for $\operatorname{SAT}\left(\sigma_{\mathrm{SAT}}=5.56 \times 10^{-2} \mathrm{~J} / \mathrm{m}^{2}\right)$. Obtained homogeneous nucleation temperature is $46^{\circ} \mathrm{C}\left(\Delta T=73^{\circ} \mathrm{C}\right)$. It was considered that the $\mathrm{S} / \mathrm{L}$ interfacial energy of the erythritol is 


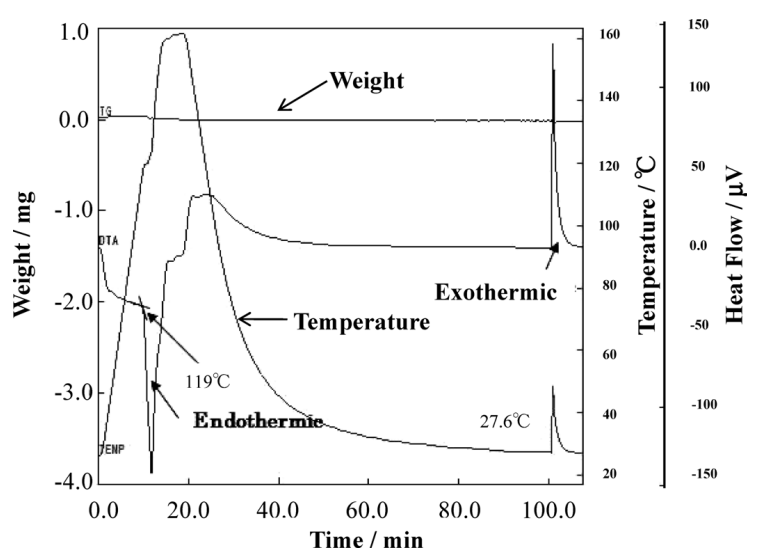

Fig. 7. TG-DTA curves of erythritol.

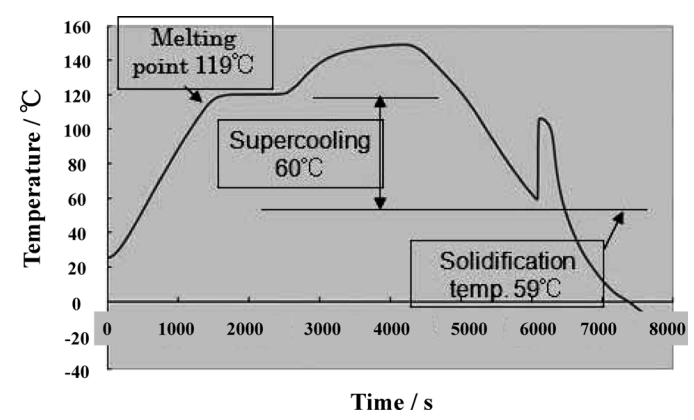

Fig. 8. Thermal analysis curve of erythritol of $20 \mathrm{~g}$ in mass.

a little bit higher than that of SAT, and the homogeneous nucleation temperature of erythritol is around room temperature.

\subsection{Inducement of Nucleation in Supercooled SAT}

To develop the supercooled thermal energy storage (super-TES) system, a technique is required for the inducement of the nucleation in the supercooled liquid of a PCM at an arbitrary moment. Certain and simple way to induce the nucleation is cooling of a PCM below homogeneous nucleation temperature. However, this way requires a low temperature heat source below $0^{\circ} \mathrm{C}$ and some sensible heat is lost from the PCM by lowering the temperature of the PCM. Hence, methods without cooling are desirable. Several techniques have been proposed for the inducement of the nucleation in supercooled liquid such as friction between metals in a supercooled liquid, addition of seed crystals into supercooled liquid, agitation of supercooling liquid, vibration and impact, electric discharge in a supercooled liquid and ultrasonic irradiation, etc. ${ }^{7-11)}$ Among these methods, ultrasonic irradiation is the ideal way because the inducement of the nucleation can be carried out with non-contact condition between a PCM and an ultrasonic generator. However, most studies for the inducement of nucleation by using the ultrasonic irradiation were concerned with supercooled water and there are a few studies concerned with PCMs. ${ }^{12-14)}$ In the present section, the effect of the ultrasonic irradiation and nucleation catalysts on the nucleation behavior of supercooled SAT was investigated.

A SAT specimen of $20 \mathrm{~g}$ in mass was melted in a glass beaker and heated to $100^{\circ} \mathrm{C}$ with heating rate of $3^{\circ} \mathrm{C} / \mathrm{min}$, then cooled to room temperature in air. The glass beaker was set in an ultrasonic scrubber with $38 \mathrm{kHz}$ frequency

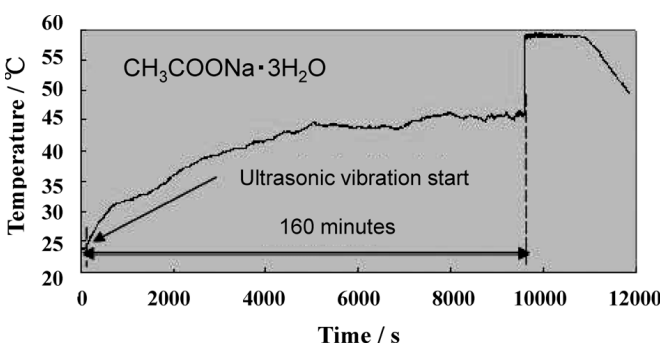

Fig. 9. Change in temperature of the sodium acetate trihydrate (SAT) of $20 \mathrm{~g}$ in mass during the ultrasonic vibration.

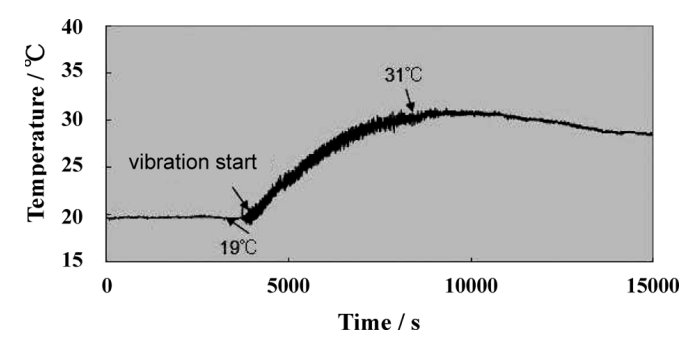

Fig. 10. Change in temperature of water during the ultrasonic vibration.

and ultrasonic irradiation was applied to the specimen as shown in Fig. 1(b). Figure 9 shows change in temperature of the specimen during the ultrasonic irradiation. The supercooled SAT specimen solidified after $160 \mathrm{~min}$ after the start of the ultrasonic irradiation. Temperature of the specimen gradually rises until the start of the solidification due to the heating effect of the ultrasonic vibration. To confirm the heating effect of the ultrasonic vibration, an experiment was carried out, in which ultrasonic vibration was applied to water without PCM specimen. Figure 10 shows change in temperature of the water during the ultrasonic irradiation. Temperature of the water gradually rose due to the heating effect of the ultrasonic vibration.

From the result shown in Fig. 9, it was seen that the inducement of the nucleation in the supercooled SAT using the ultrasonic irradiation requires a long time. Hence, we have tried to combine the ultrasonic irradiation and the addition of a nucleation catalyst into supercooled SAT. Figure 11 shows the change in the temperature of the supercooled SAT with the addition of $0.1 \mathrm{~g}$ starch. The supercooled SAT specimen solidified after 43 min from the start of the ultrasonic irradiation. Figure 12 shows the change in the temperature of the supercooled SAT with the addition of $0.2 \mathrm{~g}$ metasilicate nonahydrate $\left(\mathrm{Na}_{2} \mathrm{SiO}_{3} \cdot 9 \mathrm{H}_{2} \mathrm{O}\right)$. The supercooled SAT specimen solidified after $13 \mathrm{~min}$ from the start of the ultrasonic vibration. These results demonstrate the effectiveness of the combination of the ultrasonic irradiation and addition of the nucleation catalysts.

\section{Conclusions}

Supercooling and subsequent solidification behavior of phase change materials (PCM) of sodium acetate trihydrate (SAT) and erythritol were studied by using a thermal analysis technique. The homogeneous nucleation temperatures of SAT and erythritol were examined based on the classical nucleation theory. The inducement of the nucleation in supercooled SAT was tried by combining the ultrasonic ir- 


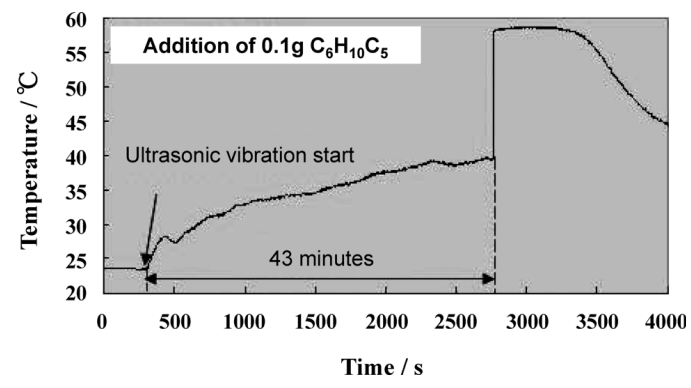

Fig. 11. Change in temperature of the sodium acetate trihydrate (SAT) with addition of $0.1 \mathrm{~g}$ starch during the ultrasonic vibration.

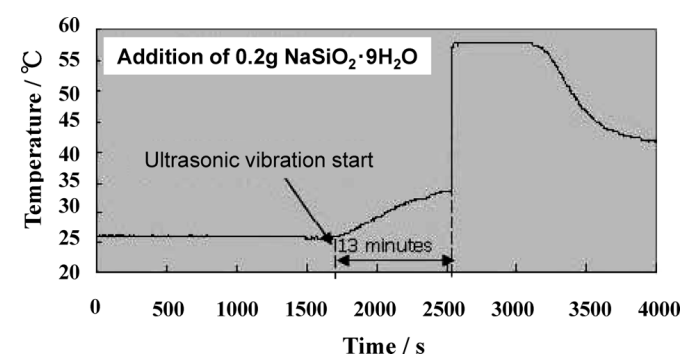

Fig. 12. Change in temperature of the sodium acetate trihydrate (SAT) with the addition of $0.2 \mathrm{~g}$ metasilicate nonahydrate during the ultrasonic vibration.

radiation and the addition of nucleation catalysts. Obtained results are summarized as follows:

(1) Three phase transformations were observed in the cooling curve of the SAT. First one is the precipitation of sodium acetate and second one is the solidification of the sodium acetate trihydrate (SAT). The third one was considered to be the solid state transformation of the SAT.
(2) The degree of the supercooling of the SAT increased with increase in the superheat and holding time of the superheated molten SAT.

(3) Based on the classical nucleation theory, the solid/liquid (S/L) interfacial energy of the SAT was evaluated as $5.56 \times 10^{-2}\left(\mathrm{~J} / \mathrm{m}^{2}\right)$.

(4) Maximum degree of erythritol measured by the thermal analysis was about $91^{\circ} \mathrm{C}$ and the homogeneous nucleation temperature of the erythritol was supposed to be around room temperature.

(5) Effectiveness of the combination of the ultrasonic irradiation and the addition of the nucleation catalysts was demonstrated for the inducement of the nucleation in the supercooled liquid SAT.

\section{REFERENCES}

1) S. Hirano and T. Saitoh: Proc. of JSES, (2000), 271

2) S. Hirano and T. Saitoh: Proc. of JSES, (2001), 307.

3) S. Hirano and T. Saitoh: Proc. of JSES, (2002), 325.

4) D. Turnbul and J. C. Fisher: J. Chem. Phys., (1949), 71.

5) D. Turnbul: J. Appl. Phys., 21 (1950), 1022.

6) W. Kurz and D. J. Fisher: Fundamentals of Solidification, Fourth Revised Ed., Trans. Tech. Publishers, Aedermannsdorf, Switzerland, (1998), 293.

7) B. Chalmers: Principles of Solidification, John Wiley \& Sons, (1964), 86.

8) J. D. Hunt and K. A. Jackson: J. Appl. Phys., 37 (1966), 254

9) S. N. Gitlin and S. S. Lin: J. Appl. Phys., 37 (1966), 254.

10) T. Wada and R. Ymamoto: Bull. Chem. Soc. Jpn., 55 (1982), 3603.

11) Y. Watanabe: Int. Symp. Indus. Cryst., Tokyo, Japan, (1998), 757.

12) S. Hirano and T. Saitoh: J. Jpn. Inst. Energy, 81 (2002), 123.

13) E. P. Ona, X. Zhang, S. Ozawa, H. Matsuda. H. Kakiuhi, M. Yabe, M. Yamazaki and M. Sato: J. Chem. Eng. Jpn., 35 (2002), 290.

14) E. Miyasak, M. Takai, H. Hidaka, Y. Kakimoto and I. Hirasawa: Ultra Sonic Sonochem., 13 (2006), 308. 